\title{
Tanshinone IIA induces apoptosis via inhibition of Wnt/ $\beta$-catenin/MGMT signaling in AtT-20 cells
}

\author{
ZONG-YANG LI*, GUO-DONG HUANG* , LEI CHEN, CE ZHANG, BAO-DONG CHEN, \\ QING-ZHONG LI, XIANG WANG, XIE-JUN ZHANG and WEI-PING LI \\ Brain Center, Shenzhen Key Laboratory of Neurosurgery, Shenzhen Second People's Hospital, \\ Shenzhen University 1st Affiliated Hospital, Shenzhen, Guangdong 518035, P.R. China
}

Received May 6, 2016; Accepted March 24, 2017

DOI: $10.3892 / \mathrm{mmr} .2017 .7325$

\begin{abstract}
A strategy to suppress the expression of the DNA repair enzyme $\mathrm{O}^{6}$-methylguanine-DNA methyltransferase (MGMT) by inhibition of Wnt/ $\beta$-catenin signaling may be useful as a novel treatment for pituitary adenoma. Previous studies have reported that Tanshinone IIA (TSA), a major quinone compound isolated from Salvia miltiorrhiza, had antitumor effects. However, whether TSA has antitumor effects against pituitary adenoma and whether the mechanisms are associated with the Wnt/ $\beta$-catenin/MGMT pathway remains to be clarified. In the present study, TSA treatment caused apoptosis in AtT-20 cells in a concentration-dependent manner, as demonstrated by cell viability reduction, phophatidylserine externalization detected by Annexin V staining and mitochondrial membrane potential disruption detected by JC-1 staining, which were associated with activation of caspase-3 and DNA fragmentation detected by TUNEL in AtT-20 cells. T-cell factor (TCF)-lymphoid-enhancing factor (LEF) reporter activity was determined by dual luciferase reporter assay and the interaction between $\beta$-catenin and TCF-4 were detected using a co-immunoprecipitation kit. The results indicated TSA treatment increased $\beta$-catenin phosphorylation, inhibited $\beta$-catenin nuclear translocation, reduced $\beta$-catenin/TCF- 4 complex formation and TCF-LEF luciferase reporter activity, and subsequently reduced the expression of cyclin D1 and MGMT. Notably, overexpression of MGMT in $\beta$-catenin knock down AtT-20 cells abrogated the TSA-mediated effects in AtT-20 cells. In conclusion, TSA induced apoptosis via inhibition of $\mathrm{Wnt} / \beta$-catenin-dependent
\end{abstract}

Correspondence to: Professor Wei-Ping Li, Brain Center, Shenzhen Key Laboratory of Neurosurgery, Shenzhen Second People's Hospital, Shenzhen University 1st Affiliated Hospital, 3002 Sungang Road, Futian, Shenzhen, Guangdong 518035, P.R. China

E-mail:wpli@szu.edu.cn

*Contributed equally

Keywords: tanshinone IIA, apoptosis, $\beta$-catenin,O6-methylguanineDNA methyltransferase
MGMT expression, which may provide novel insights into the understanding of the mechanism of the antitumor effects of Salvia miltiorrhiza.

\section{Introduction}

Pituitary adenomas account for $\sim 10 \%$ of intracranial tumors, and $5 \%$ are locally invasive (1). Although the etiology of pituitary adenoma is not fully understood, numerous experimental and clinical observations indicate that DNA repair enzyme $\mathrm{O}^{6}$-methylguanine-DNA methyltransferase (MGMT) is implicated in the pathogenesis of various tumor types, including pituitary adenoma $(2,3)$. MGMT is a ubiquitous highly expressed enzyme that removes alkylating lesions at the $\mathrm{O}^{6}$ position of guanine to repair DNA damage (4).

MGMT is regulated by multiple molecular mechanisms, including epigenetic silencing of the MGMT gene by promoter methylation, histone modifications and aberrant expression of transcriptional activators and repressors, microRNAs and activation of the canonical $\mathrm{Wnt} / \beta$-catenin signaling cascade (5). In the absence of Wnt ligands, cytoplasmic $\beta$-catenin is phosphorylated and degraded by the proteasome. However, a large pool of soluble non-phosphorylated $\beta$-catenin exists in the presence of Wnt ligands. $\beta$-catenin is then translocated to the nucleus where it interacts with T-cell factor (TCF)/lymphoid-enhancing factor (LEF) family transcription factors, such as TCF-4, to activate Wnt pathway target genes, including cyclin D1 and MGMT (6). In fact, growing evidence indicates that inhibition of $\mathrm{Wnt} / \beta$-catenin signaling may have antitumor effects (7).

Tanshinone IIA (TSA) is the main quinone compounds isolated from Salvia miltiorrhiza, which have been used for various medicinal purposes in traditional Chinese medicine for many years. Experimental and clinical studies suggest that TSA has antitumor effects $(8,9)$. Whether TSA has antitumor effects against pituitary adenomas, and whether the mechanisms are associated with $\mathrm{Wnt} / \beta$-catenin/MGMT signaling remains to be clarified.

In the present study, AtT-20 mouse pituitary cells were used to evaluate the potential antitumor effect of TSA against pituitary adenoma and the underlying mechanism. Wnt/ $\beta$-catenin/MGMT pathway inactivation was involved in antitumor effect of TSA against pituitary adenoma. 


\section{Materials and methods}

Reagents. TSA (purity $>98 \%$ ), dimethyl sulfoxide (DMSO) and 4',6-diamidino-2-phenylindole (DAPI) were purchased from Sigma-Aldrich (Merck KGaA, Darmstadt, Germany). Dulbecco's modified Eagle's medium (DMEM), fetal bovine serum (FBS) and phosphate-buffered saline (PBS) were purchased from Gibco (Thermo Fisher Scientific, Inc., Waltham, MA, USA). 3-(4,5-dimethylthiazol-2-yl)-2,5-diphenyltetrazolium bromide (MTT) and 5,5',6,6'-tetrachloro-1,1', 3,3'-tetraethylbenzimidazolylcarbocyanine iodide (JC-1) were obtained from Enzo Life Sciences, Inc. (Farmingdale, NY, USA). Cell nuclear protein extraction kits, MGMT lentiviral activation particles and and control lentiviral activation particles, $\beta$-catenin short hairpin RNA (shRNA) lentiviral particle and control shRNA plasmid, Polybrene, and puromycin dihydrochloride were obtained from Santa Cruz Biotechnology, Inc. (Dallas, TX, USA).

Cell culture and drug preparation. AtT-20 cells obtained from the Typical Culture Preservation Commission Cell Bank, Chinese Academy of Sciences (Shanghai, China) were cultured at $37^{\circ} \mathrm{C}$ in $5 \% \mathrm{CO}_{2}$ and $95 \%$ atmosphere in DMEM medium supplemented with 5\% FBS and glutamine (2 mM). To overexpress MGMT in $\beta$-catenin knock down cells, AtT-20 cells were cultured in 6 -well plate $\left(5 \times 10^{4}\right.$ cells $\left./ \mathrm{ml}\right)$ and cultured to $60 \%$ confluency. Cells were transfected with MGMT lentiviral activation particles $\left(1 \times 10^{5} / \mathrm{ml}\right)$ and $\beta$-catenin shRNA lentiviral particle $\left(1 \times 10^{5} / \mathrm{ml}\right)$ in complete medium with Polybrene $(5 \mu \mathrm{g} / \mathrm{ml})$ and incubated overnight. Stable clones were selected using puromycin dihydrochloride $(5 \mu \mathrm{g} / \mathrm{ml})$. The mRNA and protein expression of $\beta$-catenin or MGMT were determined by reverse transcription-polymerase chain reaction (RT-PCR) and western blotting, respectively. TSA stock solution (1 M) was prepared in DMSO and diluted with fresh complete medium immediately prior to use. The control cells were treated with DMSO (final concentration $<0.1 \%$ ).

Analysis of cell viability. Cell viability was determined by MTT assay. AtT-20 cells $\left(5 \times 10^{4}\right.$ cells $\left./ \mathrm{ml}\right)$ were seeded in 96-well plates and incubated overnight. After TSA $(2.5,5,10$, $20 \mu \mathrm{M})$ treatment for $4,8,12,16$ or $24 \mathrm{~h}$, cells were incubated at $37^{\circ} \mathrm{C}$ for $4 \mathrm{~h}$ with MTT solution $(1 \mathrm{mg} / \mathrm{ml})$, and then added $100 \mu 1 \mathrm{DMSO}$ to dissolve formazan crystals. The absorbance was detected on a microplate reader $(570 \mathrm{~nm}$; Tecan Group Ltd., Männedorf, Austria). Cell viability was expressed as a percentage of the control group.

LDH leakage assay. AtT-20 cells $\left(5 \times 10^{4}\right.$ cells $\left./ \mathrm{ml}\right)$ were seeded in 6-well plates and incubated overnight. Following TSA treatment $(5,10,20 \mu \mathrm{M})$ for $4,8,12,16$ or $24 \mathrm{~h}$, the culture medium was used to measure the amounts of lactate dehydrogenase (LDH) released using an LDH assay kit (Nanjing Jiancheng Bioengineering Institute, Nanjing, China), according to the manufacturer's protocol.

Terminal deoxynucleotidyl transferase dUTP nick endlabeling (TUNEL).TUNEL kits (EMD Millipore, Billerica, MA, USA) were used to detect DNA fragmentation of apoptotic AtT-20 cells. AtT-20 cells $\left(1 \times 10^{5}\right.$ cells $\left./ \mathrm{ml}\right)$ were seeded in
6 -well plates and treated with increasing concentrations of TSA $(5,10$, and $20 \mu \mathrm{M})$ for $12 \mathrm{~h}$. Cells were incubated at $37^{\circ} \mathrm{C}$ for $1 \mathrm{~h}$ with terminal deoxynucleotidyl transferase enzyme, and then incubated for $30 \mathrm{~min}$ with the anti-digoxigenin conjugate. The cell nuclei were counterstained with DAPI. The fluorescence images were captured by a fluorescence microscope (Leica Microsystems GmbH, Wetzlar, Germany).

Quantification of the apoptosis rate. The apoptosis rate was detected by Annexin V/propidium iodide (PI) assay kits (Invitrogen; Thermo Fisher Scientific, Inc.). AtT-20 cells $\left(1 \times 10^{5}\right.$ cells $\left./ \mathrm{ml}\right)$ were cultured in 6 -well plates and treated with increasing concentrations of TSA $(5,10$ and $20 \mu \mathrm{M})$ for $12 \mathrm{~h}$. Cells were incubated for $15 \mathrm{~min}$ with Annexin V/PI $(1 \mu \mathrm{g} / \mathrm{ml})$ solution, and then analyzed using a FACSCalibur flow cytometer. Data were analyzed using CellQuest Pro software v1.0 (BD Biosciences, San Jose, CA, USA).

Detection of mitochondrial membrane potential. The mitochondrial membrane potential was detected using JC-1. AtT-20 cells $\left(1 \times 10^{5}\right.$ cells $\left./ \mathrm{ml}\right)$ were cultured in 6 -well plates and treated with increasing concentrations of TSA $(5,10$ and $20 \mu \mathrm{M}$ ) for $12 \mathrm{~h}$. Cells were then incubated at $37^{\circ} \mathrm{C}$ for $30 \mathrm{~min}$ with JC-1 $(2 \mu \mathrm{M})$ and analyzed using a FACSCalibur flow cytometer.

Detection of caspase-3 activity. The caspase-3 activity was determined using a fluorescein-based active caspase-3 staining kit (BioVision, Inc., Milpitas, CA, USA). AtT-20 cells $\left(1 \times 10^{5}\right.$ cells $\left./ \mathrm{ml}\right)$ were cultured in 6 -well plates and treated with increasing concentrations of TSA $(5,10$ and $20 \mu \mathrm{M}$ ) for $12 \mathrm{~h}$. Cells were incubated for $10 \mathrm{~min}$ in chilled lysis buffer and then incubated at $37^{\circ} \mathrm{C}$ for additional $2 \mathrm{~h}$ in reaction buffer (containing $10 \mathrm{mM}$ dithiothreitol and DEVD-7-amino-4-trifluoromethylcoumarin substrate). The fluorescence was detected using a microplate reader (excitation, $400 \mathrm{~nm}$; emission, $505 \mathrm{~nm}$ ). The caspase-3 activity was expressed as the percentage of the control.

Dual luciferase reporter assay. TCF-LEF reporter activity was determined using a dual luciferase reporter assay. A TCF-LEF reporter, obtained from SABiosciences (Qiagen, Inc., Valencia, CA, USA) is a mixture of inducible TCF-LEF-responsive firefly luciferase construct and constitutively expressed Renilla luciferase construct (40:1). AtT-20 cells ( $1 \times 10^{5}$ cells/well) were seeded in 6-well plates. When $60 \%$ confluence was observed, the cells were transiently transfected with TCF-LEF reporter using Lipofectamine 2000 (Thermo Fisher Scientific, Inc.). At $24 \mathrm{~h}$ after transfection, cells were treated with increasing concentrations of TSA $(5,10$ and $20 \mu \mathrm{M})$ for $12 \mathrm{~h}$. TCF-LEF reporter activity was measured using the dual luciferase reporter assay system (Promega Corporation, Madison, WI, USA). Luciferase activity was detected busing a GloMaxTM 96 microplate luminometer (Promega Corporation) The firefly luciferase values were normalized to the Renilla luciferase values. TCF-LEF activity was expressed as a percentage of the control.

Co-immunoprecipitation (co-IP). The interaction between $\beta$-catenin and TCF-4 was detected using a Pierce 


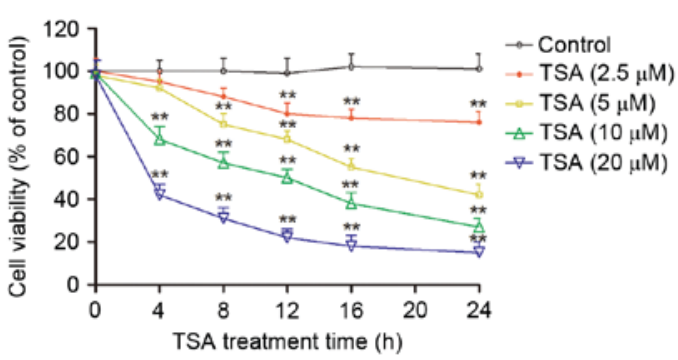

C
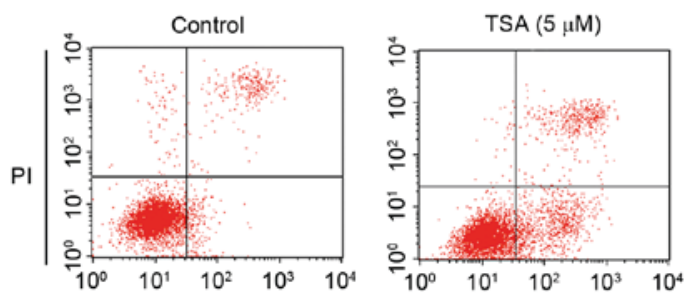

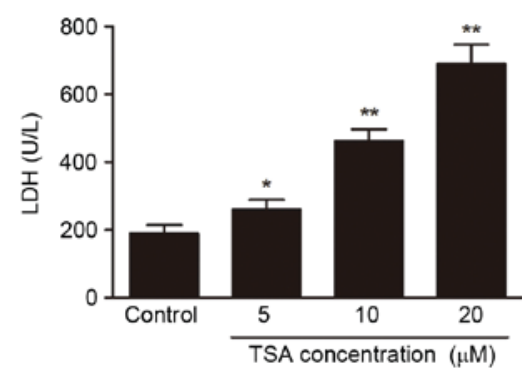

D

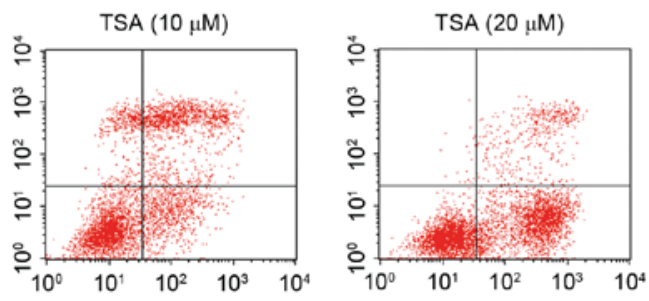

Annexin V
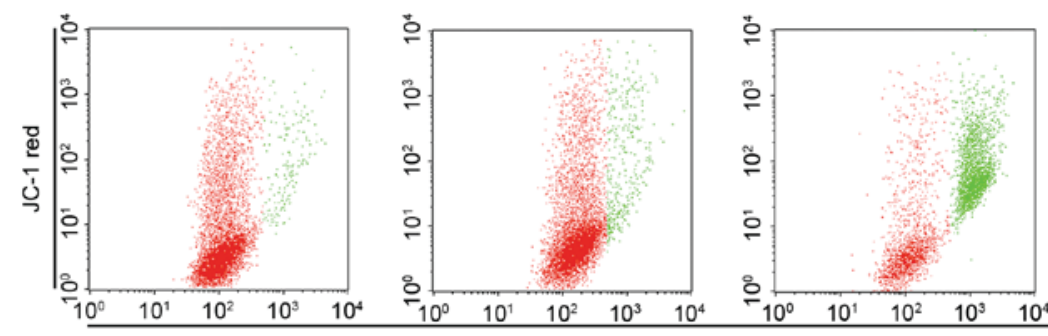

JC-1 green

E

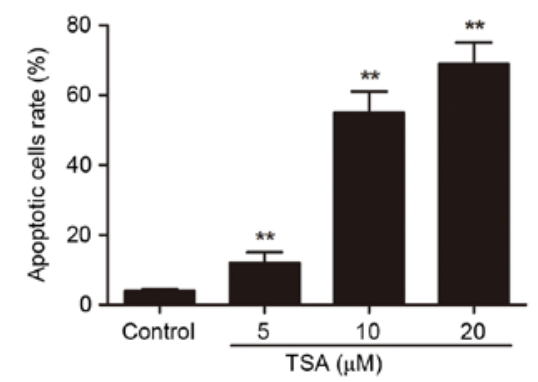

$\mathrm{F}$

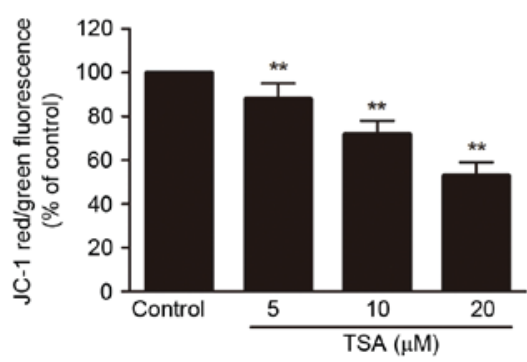

Figure 1. TSA induced apoptosis in AtT-20 cells. (A) TSA reduced the cell viability in a dose-dependent manner. (B) TSA increased the LDH leakage in a dose-dependent manner. (C) TSA increased the apoptotic cells rate in a dose-dependent manner. (D) TSA induced the mitochondrial membrane potential disruption in a dose-dependent manner. (E) Quantification of the apoptotic cells rate. (F) Quantification of JC-1 red/green fluorescence. ${ }^{*} \mathrm{P}<0.05,{ }^{* *} \mathrm{P}<0.01 \mathrm{vs}$. control. TSA, Tanshinone IIA; LDH, lactate dehydrogenase.

co-immunoprecipitation kit (Thermo Fisher Scientific, Inc.). Briefly, AtT-20 cells ( $1 \times 10^{5}$ cells/well) were treated with increasing concentrations of TSA $(5,10$ and $20 \mu \mathrm{M})$ for $12 \mathrm{~h}$. The nuclear protein was obtained using cell nuclear protein extraction kits (Thermo Fisher Scientific, Inc.) and pre-cleared using the control agarose resin, and then incubated at $4^{\circ} \mathrm{C}$ with antibody against TCF-4 (1:200; ab185736, Abcam, Cambridge, MA, USA) immobilized to AminoLink Plus (Thermo Fisher Scientific, Inc.) coupling resin in reaction buffer. Immunoprecipitates were washed with lysis buffer and eluted with elution buffer. The level of $\beta$-catenin was analyzed by western blotting.
Western blot. The expression level of protein was analyzed by western blot. The total cytosol and nuclear protein extract were prepared using cell cytosol and nuclear protein extraction kits (Thermo Fisher Scientific, Inc.), respectively. The total protein concentration was determined using a bicinchonic acid assay. Proteins $(20 \mu \mathrm{g})$ were resolved by $10 \%$ SDS-PAGE and transferred on PVDF membranes. The membranes were blocked with 2\% BSA (Sigma-Aldrich; Merck KGaA) in TBS-Tween-20 $(0.1 \%)$ at $4^{\circ} \mathrm{C}$ for $1 \mathrm{~h}$. The membranes were incubated overnight at $4^{\circ} \mathrm{C}$ with the following primary antibodies: $\beta$-catenin (C-18; sc-1496; 1:200) p- $\beta$-catenin (Ser 33; sc-101650; 1:200), TCF-4 (F-7; sc-271288; 1:200), $\beta$-actin 
A
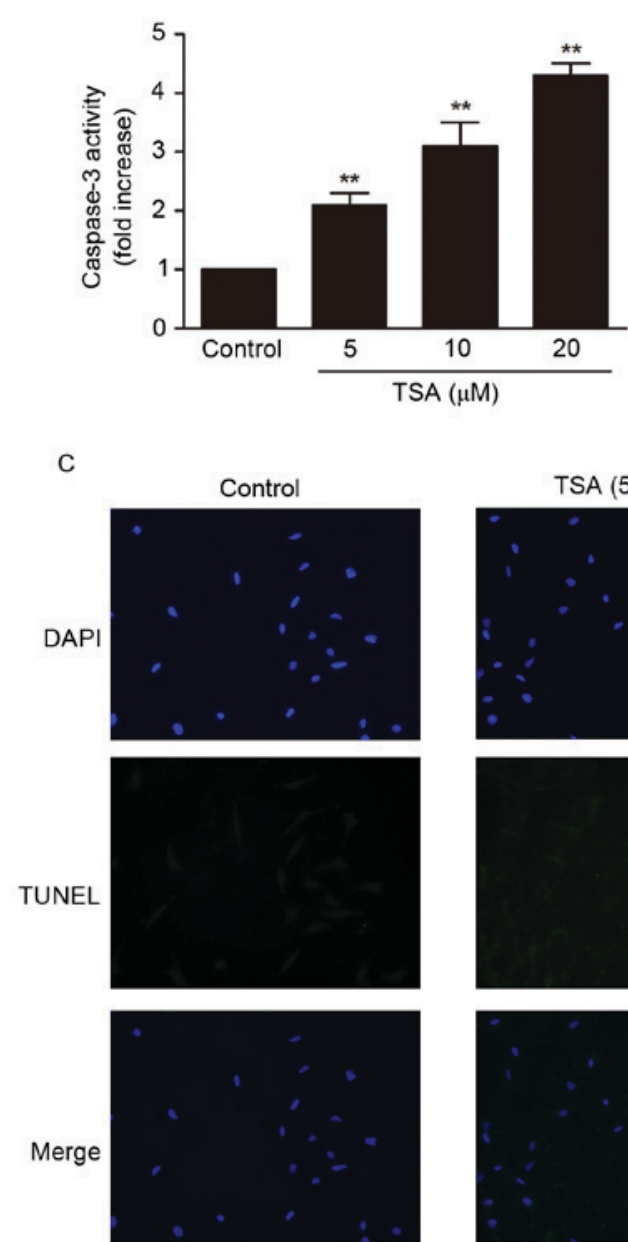
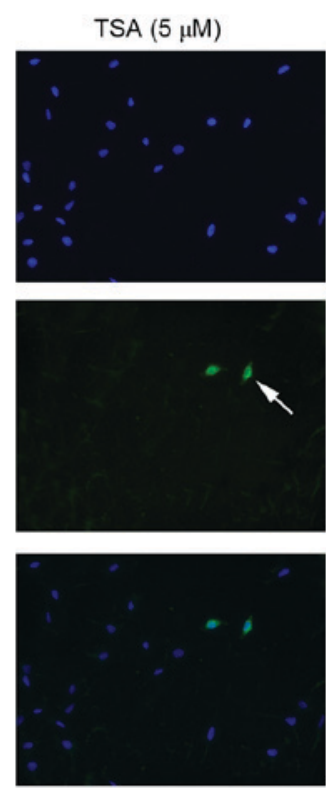
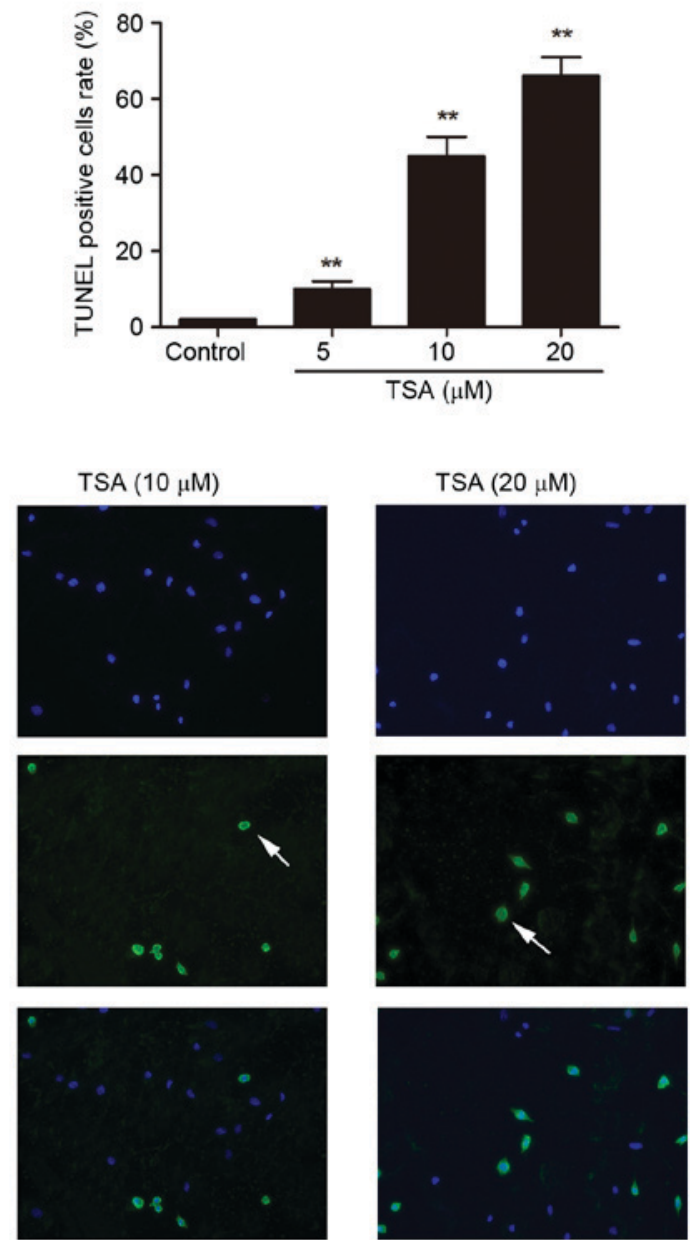

Figure 2. TSA induces caspase-3 activation and DNA fragmentation in AtT-20 cells. (A) TSA increased caspase-3 activity in a dose-dependent manner. (B) Quantification of TUNEL-positive cells rate. (C) TSA induced DNA fragmentation in AtT-20 cells in a dose-dependent manner. ** P<0.01 vs. control. TSA, Tanshinone IIA; TUNEL, terminal deoxynucleotidyl transferase dUTP nick-end labeling.

(C-2; sc-8432; 1:1,000) and lamin B (C-20; sc-6216; 1:200) from Santa Cruz Biotechnology, Inc., and cyclin D1 (ab134175; 1:1,000), MGMT (ab39253; 1:1,000) from Abcam (Cambridge, MA, USA). The membranes were incubated at $4^{\circ} \mathrm{C}$ for $1 \mathrm{~h}$ with respective horseradish peroxidase-conjugated goat anti-mouse (ab6789, Abcam, Cambridge, MA, USA) or goat anti-rabbit second antibodies (ab6721, Abcam, Cambridge, MA, USA). The immunoblots were visualized using enhanced chemiluminescence western blot detection kits (GE Healthcare Life Sciences, Chalfont, UK) and then visualized using a molecular imager with Image Lab 3.0 (Bio-Rad Laboratories, Inc., Hercules, CA, USA). Equal loading of proteins was determined by $\beta$-actin or lamin $B$. The expression levels of the proteins were quantified using a densitometer (Molecular Devices, LLC, Sunnyvale, CA, USA).

Statistical analysis. The data represent the results from three independent experiments. The results are presented as the mean \pm standard error of the mean. Student's two-tailed t-test and one-way ANOVA followed by Bonferroni's multiple comparison test were used for comparison between two groups and multiple groups, respectively. $\mathrm{P}<0.05$ was considered statistically significant.

\section{Results}

TSA induces apoptosis in AtT-20 cells. The potential antitumor effect of TSA against AtT-20 cells was investigated. Treatment of AtT-20 cells with increasing concentrations of TSA for increasing periods of time reduced the cell viability $(\mathrm{P}<0.01$, Fig. 1A) and increase LDH leakage $(\mathrm{P}<0.01$; Fig. 1B) in concentration- and time-dependent manners.

Phophatidylserine externalization, depolarization of mitochondrial membrane, caspase-3 activation and DNA fragmentation are the main features of apoptotic cells (10), and were detected by annexin V/PI staining and JC-1 staining (Fig. 1C-F), and caspase-3 activity assay (Fig. 2A) and TUNEL staining (Fig. 2B and C), respectively. TSA treatment significantly increased the percentage of apoptotic cells $(\mathrm{P}<0.01$; Fig. 1C and E) and decreased mitochondrial membrane potential $(\mathrm{P}<0.01$; Fig. 1D and $\mathrm{F})$ compared with the control. Compared with the control group, caspase-3 activity $(\mathrm{P}<0.01$; Fig. 2A) and TUNEL-positive cell rate $(\mathrm{P}<0.01$; Fig. $2 \mathrm{~B}$ and $\mathrm{C}$ ) were increased by TSA in a dose-dependent manner.

TSA inhibited Wnt/ $\beta$-catenin/MGMT pathway in AtT-20 cells. Dysregulation of the Wnt/ $\beta$-catenin/MGMT pathway 
A
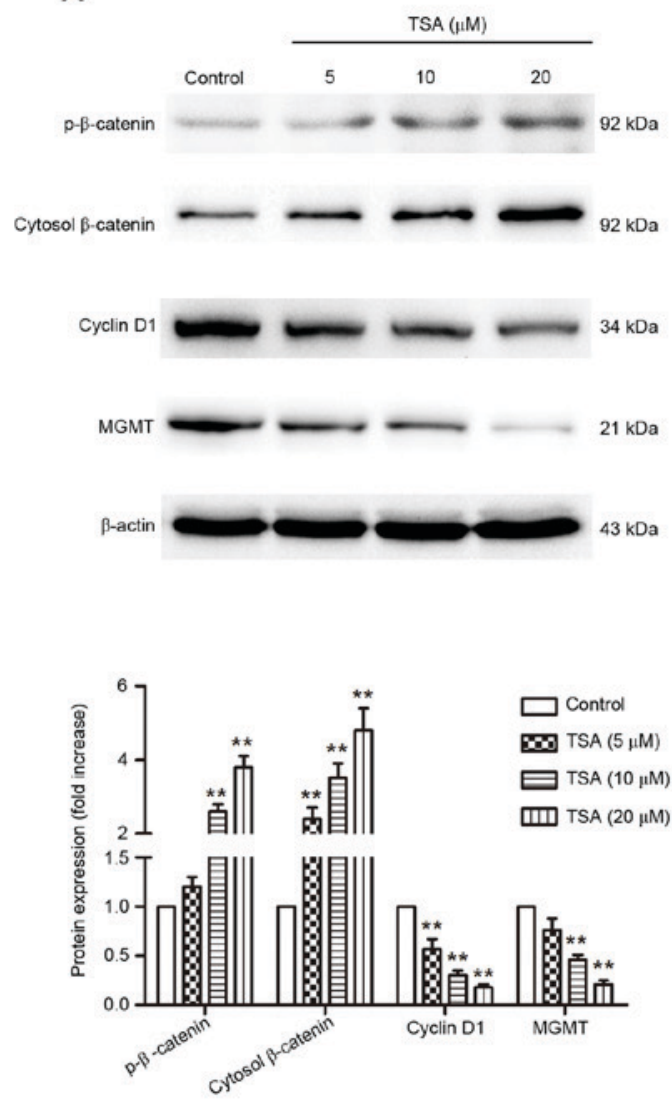

C

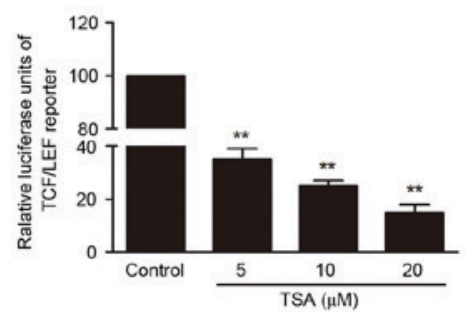

B
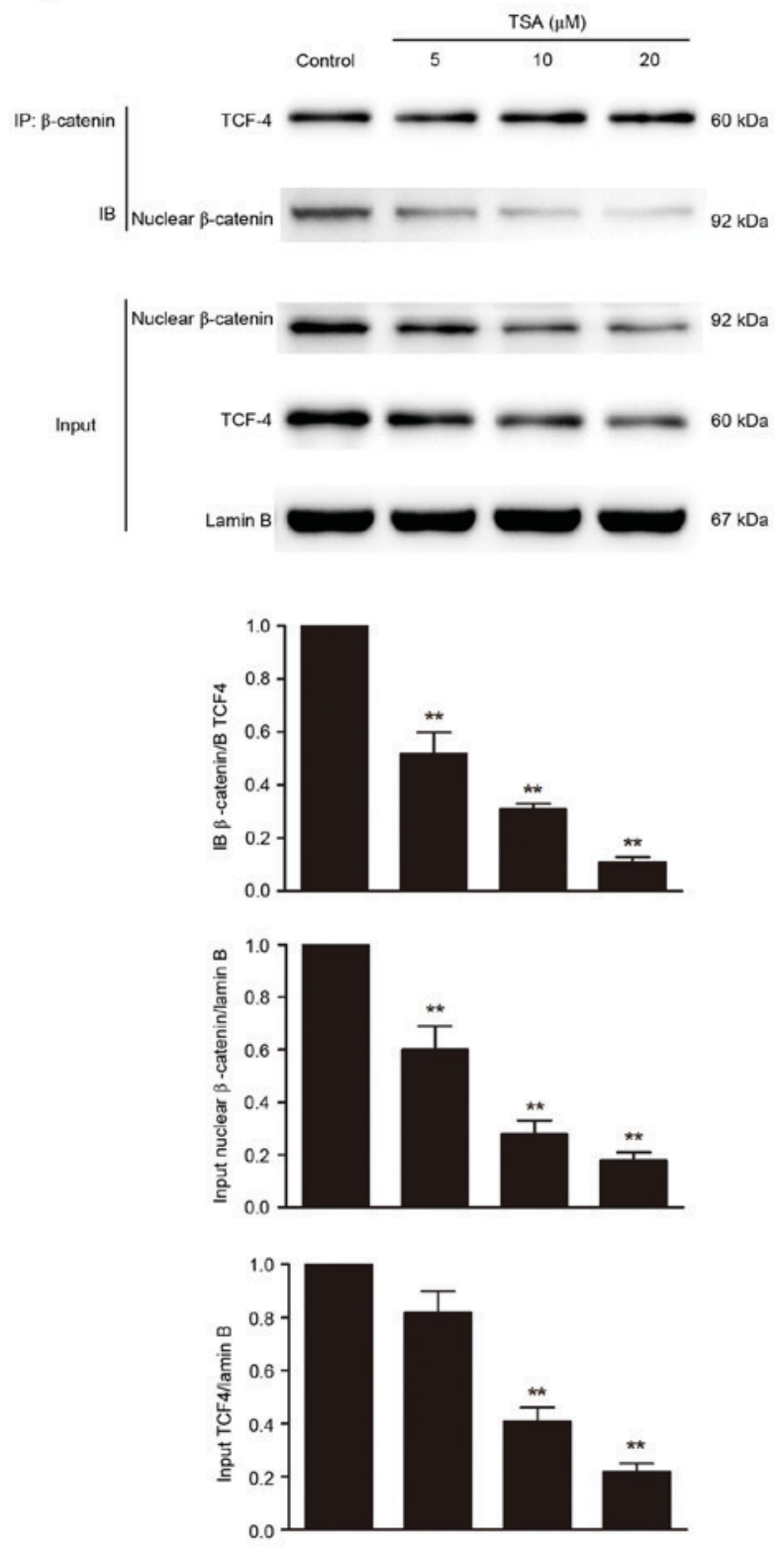

Figure 3. TSA inhibits Wnt/ $\beta$-catenin/MGMT pathway. (A) The protein expression of $\mathrm{p}$ - $\beta$-catenin, cytosol $\beta$-catenin, cyclin D1 and MGMT determined by western blot. (B) The levels of $\beta$-catenin/TCF-4 complex detected by co-IP. (C) TCF-LEF reporter luciferase activity measured using the dual luciferase reporter assay system. ${ }^{* *} \mathrm{P}<0.01$ vs. control. TSA, Tanshinone IIA; MGMT, $\mathrm{O}^{6}$-methylguanine-DNA methyltransferase; TCF-4, T-cell factor; LEF, lymphoid-enhancing factor; IP, co-immunoprecipitation; IB, immunoblot.

has a pivotal role in the pathogenesis of pituitary adenoma. A strategy to suppress the expression of MGMT by inhibition of Wnt/ $\beta$-catenin signaling may be useful as a novel treatment for pituitary adenoma. Thus, whether TSA affects the Wnt/ $\beta$-catenin/MGMT pathway was investigated. TSA treatment increased $\beta$-catenin phosphorylation and inhibited nuclear translocation of $\beta$-catenin in a dose-dependent manner $(\mathrm{P}<0.01$; Fig. 3A and B). The levels of cyclin D1 and MGMT were detected to determine whether the inactivation of $\beta$-catenin mediated by TSA decreases the transcription of target genes. The protein levels of cyclin D1 and MGMT were significantly decreased by TSA treatment compared with the control $(\mathrm{P}<0.01$; Fig. 3A). Importantly, co-IP results indicated that the interaction between $\beta$-catenin and TCF- 4 was significantly reduced by TSA treatment in a dose-dependent manner (Fig. $3 \mathrm{~B}, \mathrm{P}<0.01$ ).
In accordance with these results, TSA treatment of AtT-20 cells transfected with a TCF-LEF reporter resulted in a dose-dependent reduction in TCF-LEF reporter activity ( $\mathrm{P}<0.01$; Fig. 3C).

TSA induces apoptosis via inhibition of Wnt/ $\beta$ catenin/MGMT pathway in AtT-20 cells. To investigate whether Wnt/ $\beta$-catenin/MGMT pathway was involved in TSA-mediated apoptosis, $\beta$-catenin knock down AtT-20 cells were infected with MGMT lentiviral activation particles. The inhibition of $\beta$-catenin nuclear translocation (Fig. 4A), decrease in TCF-LEF reporter activity (Fig. 4B, P<0.01), reduction in MGMT expression (Fig. 4A), phophatidylserine externalization (Fig. 4C), caspase-3 activation (Fig. 4D), DNA fragmentation (Fig. 4E), LDH leakage (Fig. 4F) and decrease in cell viability (Fig. 4G) induced by TSA were all 
A
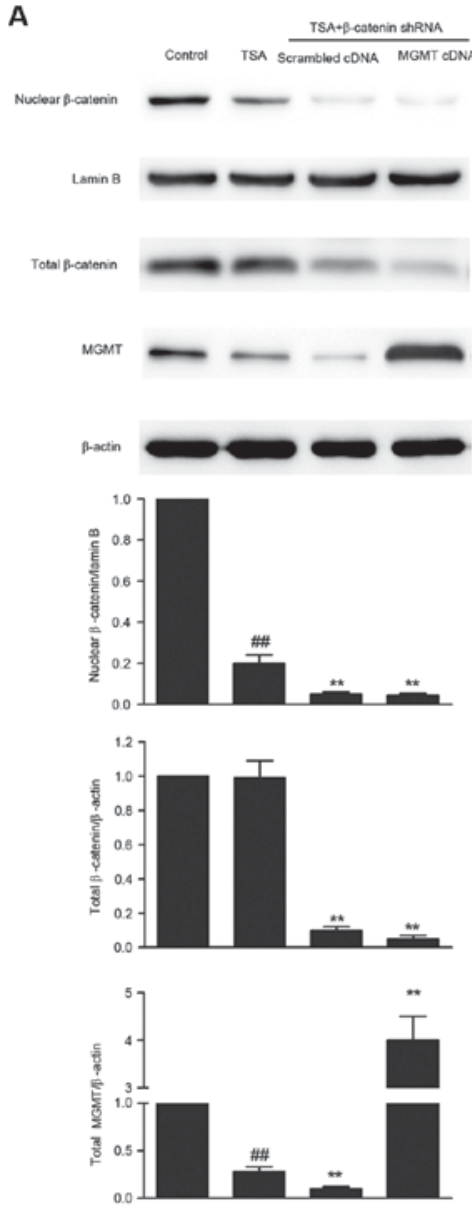

B

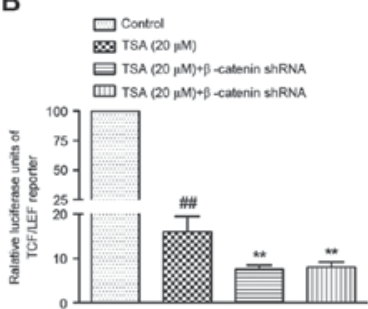

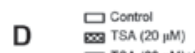

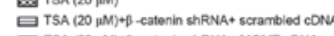

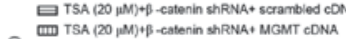

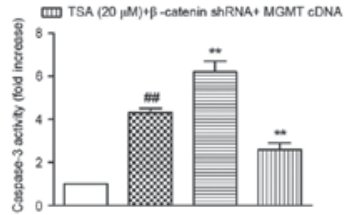

$\mathbf{F}$

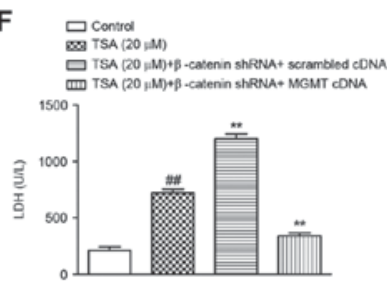

C

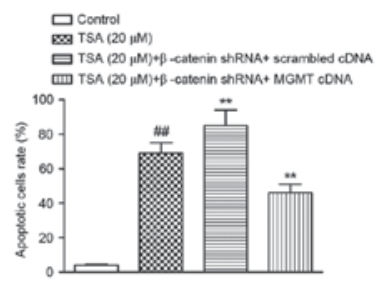

$\mathrm{E}$

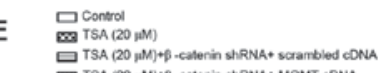

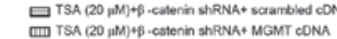

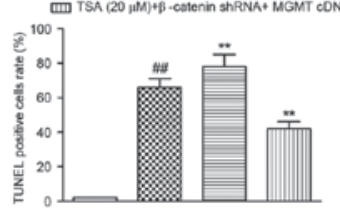

G

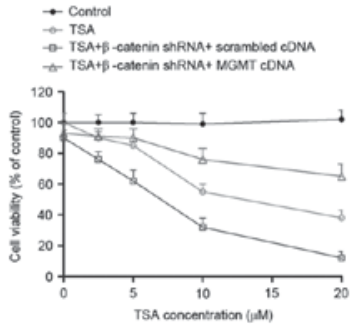

Figure 4. MGMT overexpression abolishes TSA-mediated apoptosis in $\beta$-catenin knock down AtT-20 cells. (A) The protein expression of nuclear $\beta$-catenin, total $\beta$-catenin and MGMT determined by western blot. (B) TCF-LEF reporter luciferase activity in $\beta$-catenin knock down AtT-20 cells. MGMT overexpression abolished TSA-mediated increase in (C) the apoptotic cells rate, (D) caspase-3 activation, (E) DNA fragmentation, (F) LDH leakage and (G) the decrease in cell viability. ${ }^{\# \#} \mathrm{P}<0.01$ vs. control; ${ }^{* *} \mathrm{P}<0.01$ vs. TSA treatment alone. TSA, Tanshinone IIA; $\mathrm{p}-\beta$-catenin; phosphorylated $\beta$-catenin; MGMT, $\mathrm{O}^{6}$-methylguanine-DNA methyltransferase; TCF-4, T-cell factor; LEF, lymphoid-enhancing factor; TUNEL, terminal deoxynucleotidyl transferase dUTP nick-end labeling; LDH, lactate dehydrogenase.

significantly augmented in $\beta$-catenin knock down AtT-20 cells $(\mathrm{P}<0.01)$. However, overexpression of MGMT in $\beta$-catenin knock down AtT-20 cells reversed TSA-mediated phophatidylserine externalization $(\mathrm{P}<0.01$; Fig. 4C), caspase-3 activation $(\mathrm{P}<0.01$; Fig. 4D), DNA fragmentation $(\mathrm{P}<0.01$; Fig. 4E), LDH leakage $(\mathrm{P}<0.01$; Fig. 4F) and decrease in cell viability $(\mathrm{P}<0.01$; Fig. $4 \mathrm{G})$, suggesting that $\mathrm{Wnt} / \beta$-catenin/MGMT inactivation is responsible for TSA-mediated antitumor effects.

\section{Discussion}

The current study confirmed that TSA induces apoptosis in AtT-20 cells. Apoptosis is generally characterized by phophatidylserine externalization, depolarization of mitochondrial membrane, caspase-3 activation and DNA fragmentation $(11,12)$. Previous studies have indicated that TSA has anti-tumor effects on glioma cells (13), osteosarcoma cells (14) and gastric cancer cells (15). In the present study, TSA treatment resulted in cell viability reduction, phophatidylserine externalization, mitochondrial membrane potential disruption, caspases-3 activation and DNA fragmentation in AtT-20 cells. These results suggest that TSA induced apoptosis in AtT-20 cells, suggesting that TSA may be a candidate drug for treatment of pituitary adenoma.

The principal finding of this study is that TSA induces apoptosis in AtT-20 cells via downregulating Wnt/ $\beta$-catenin/MGMT signaling. The canonical Wnt/ $\beta$-catenin cascade, thenon-canonical planar cell polarity pathway and the $\mathrm{Wnt} / \mathrm{Ca}^{2+}$ pathway are involved in Wnt receptor activation (16). The Wnt/ $\beta$-catenin pathway can regulate MGMT gene expression in cancer, and inhibition of Wnt signalling can prevent chemoresistance (17). Dysregulation of the Wnt/ $\beta$-catenin/MGMT pathway has a pivotal role in the pathogenesis of pituitary adenoma $(18,19)$. In the present study, TSA increased the phosphorylation of $\beta$-catenin, and inhibited its nuclear translocation in AtT-20 cells. Notably, co-IP results revealed that $\beta$-catenin/TCF-4 binding was significantly reduced by TSA treatment, meanwhile, TSA treatment of AtT-20 cells transiently transfected with TCF-LEF reporter resulted in a marked decrease in TCF-LEF activity. These results indicated that when activated $\beta$-catenin translocated to the nucleus, combined with TCF-4 and interacted with TCF-LEF, resulting in transcription of target genes, including cyclin D1 and MGMT. The results of the present study are in agreement with a previous study, which observed that TSA inhibited the transdifferentiation 
of renal tubular epithelial cells induced by high glucose via downregulation of the Wnt/beta-catenin signaling pathway activity (20).

Notably, TSA-mediated suppression of $\mathrm{Wnt} / \beta$ catenin/MGMT pathway and apoptosis were exacerbated in $\beta$-catenin KO cells, however, TSA-mediated apoptosis was abolished by MGMT overexpression in $\beta$-catenin knock down cells. To the best of our knowledge, this study is the first to demonstrate that $\mathrm{Wnt} / \beta$-catenin/MGMT inactivation is mediates for TSA-induced apoptosis in AtT-20 cells.

In conclusion, TSA induced apoptosis by inactivating the Wnt/ $\beta$-catenin/MGMT pathways in AtT-20 cells, which provides a novel insight into the mechanism underlying the antitumor effects of Salvia miltiorrhiza extract. The results of the present study must be further investigated, particularly through the use of an in vivo model.

\section{Acknowledgements}

This project was supported by the Basic research projects of Shenzhen Science and Technology Program (grant nos. JCYJ20140414170821309, JCYJ20150306114616, JCYJ20150330102720152 and JCYJ2920831101643895), the Natural Science Foundation of Guangdong (grant no. 2015A030313777), the Research Fund from Shenzhen Key Laboratory of Neurosurgery (grant no. ZDSYS20140509173142601).

\section{References}

1. Gurcan O, Gurcay AG, Kazanci A, Yildirim AE, Turkoglu OF, Komurcu HF and Beskonakli E: Trigeminal neuralgia as an unusual isolated symptom of pituitary Adenoma: Case report and review of the literature. Turk Neurosurg 26: 180-183, 2016.

2. Bengtsson D, Schrøder HD, Andersen M, Maiter D, Berinder K, Feldt Rasmussen U, Rasmussen ÅK, Johannsson G, Hoybye C, van der Lely AJ, et al: Long-term outcome and MGMT as a predictive marker in 24 patients with atypical pituitary adenomas and pituitary carcinomas given treatment with temozolomide. J Clin Endocrinol Metab 100: 1689-1698, 2015.

3. McCormack A, Kaplan W, Gill AJ, Little N, Cook R, Robinson B and Clifton-Bligh R: MGMT expression and pituitary tumours: Relationship to tumour biology. Pituitary 16: 208-219, 2013.

4. Chen YP, Hou XY, Yang CS, Jiang XX, Yang M, Xu XF, Feng SX, Liu YQ and Jiang G: DNA methylation and histone acetylation regulate the expression of MGMT and chemosensitivity to temozolomide in malignant melanoma cell lines. Tumour Biol 37 11209-11218, 2016.
5. Wickström M, Dyberg C, Milosevic J, Einvik C, Calero R, Sveinbjörnsson B, Sandén E, Darabi A, Siesjö P, Kool M, et al: Wnt/ $\beta$-catenin pathway regulates MGMT gene expression in cancer and inhibition of Wnt signalling prevents chemoresistance 6: 8904, 2015.

6. Khattak MN, Buchfelder M, Kleindienst A, Schöfl C and Kremenevskaja N: CRH and SRIF have opposite effects on the Wnt/ $\beta$-catenin signalling pathway through PKA/GSK-3 $\beta$ in corticotroph pituitary cells. Cancer Invest 28: 797-805, 2010.

7. Das A, Miller R, Lee P, Holden CA, Lindhorst SM, Jaboin J, Vandergrift WA III, Banik NL, Giglio P, Varma AK, et al: A novel component from citrus, ginger, and mushroom family exhibits antitumor activity on human meningioma cells through suppressing the $\mathrm{Wnt} / \beta$-catenin signaling pathway. Tumour Biol 36: 7027-7034, 2015.

8. Xing Y, Tu J, Zheng L, Guo L and Xi T: Anti-angiogenic effect of tanshinone IIA involves inhibition of the VEGF/VEGFR2 pathway in vascular endothelial cells. Oncol Rep 33: 163-170, 2015.

9. Bai Y, Zhang L, Fang X and Yang Y: Tanshinone IIA enhances chemosensitivity of colon cancer cells by suppressing nuclear factor-кB. Exp Ther Med 11: 1085-1089, 2016.

10. Prokhorova EA, Zamaraev AV, Kopeina GS, Zhivotovsky B and Lavrik IN: Role of the nucleus in apoptosis: Signaling and execution. Cell Mol Life Sci 72: 4593-4612, 2015.

11. Jellinger KA: Challenges in neuronal apoptosis. Curr Alzheimer Res 3: 377-391, 2006.

12. Hunter AL, Choy JC and Granville DJ: Detection of apoptosis in cardiovascular diseases. Methods Mol Med 112: 277-289, 2005.

13. Ding L, Ding L, Wang S, Wang S, Wang W, Wang W, Lv P, Lv P, Zhao D, Zhao D, et al: Tanshinone IIA affects autophagy and apoptosis of glioma cells by inhibiting phosphatidylinositol 3-kinase/Akt/mammalian target of rapamycin signaling pathway. Pharmacology 99: 188-195, 2017.

14. Huang ST, Huang CC, Huang WL, Lin TK, Liao PL, Wang PW, Liou CW and Chuang JH: Tanshinone IIA induces intrinsic apoptosis in osteosarcoma cells both in vivo and in vitro associated with mitochondrial dysfunction. Sci Rep 7: 40382, 2017.

15. Yu J, Wang X, Li Y and Tang B: Tanshinone IIA suppresses gastric cancer cell proliferation and migration by downregulation of FOXM1. Oncol Rep 37: 1394-1400, 2017.

16. Clevers H: Wnt/beta-catenin signaling in development and disease. Cell 127: 469-480, 2006.

17. Wickström M, Dyberg C, Milosevic J, Einvik C, Calero R, Sveinbjörnsson B, Sandén E, Darabi A, Siesjö P, Kool M, et al: Wnt $/ \beta$-catenin pathway regulates MGMT gene expression in cancer and inhibition of Wnt signalling prevents chemoresistance. Nat Commun 6: 8904, 2015.

18. Formosa R, Gruppetta M, Falzon S, Santillo G, DeGaetano J, Xuereb-Anastasi A and Vassallo J: Expression and clinical significance of Wnt players and survivin in pituitary tumours. Endocr Pathol 23: 123-131, 2012.

19. Maïza JC and Caron P: Pituitary carcinomas and aggressive adenomas: An overview and new therapeutic options. Ann Endocrinol (Paris) 70 (Suppl 1): S12-S19, 2009 (In French).

20. Huang BY, Cao LY and Fu XG: Effects of tanshinone IIA on Wnt/beta-catenin signaling pathway of high glucose induced renal tubular epithelial cell transdifferentiation. Zhongguo Zhong Xi Yi Jie He Za Zhi 32: 965-969, 2012 (In Chinese). 